\title{
Malachite Green Removal by Activated Potassium Hydroxide Clove Leaf Agrowaste Biosorbent: Characterization, Kinetic, Isotherm, and Thermodynamic Studies
}

\author{
Dyan Hatining Ayu Sudarni, ${ }^{1}$ Uyiosa Osagie Aigbe $\mathbb{D}^{2},{ }^{2}$ Kingsley Eghonghon Ukhurebor $\left(\mathbb{D},{ }^{3}\right.$ \\ Robert Birundu Onyancha $\complement^{4},{ }^{4}$ Heri Septya Kusuma ${ }^{1},{ }^{5}$ Handoko Darmokoesoemo, ${ }^{6}$ \\ Otolorin Adelaja Osibote, ${ }^{2}$ Vincent Aizebeoje Balogun, ${ }^{7}$ and Bernadeta Ayu Widyaningrum ${ }^{8}$ \\ ${ }^{1}$ Department of Chemical Engineering, Faculty of Engineering, Universitas PGRI Madiun, Indonesia \\ ${ }^{2}$ Department of Mathematics and Physics, Faculty of Applied Sciences, Cape Peninsula University of Technology, P.O. Box 1906, \\ Cape Town, South Africa \\ ${ }^{3}$ Department of Physics, Faculty of Science, Edo State University Uzairue, P.M.B 04, Auchi, 312101 Edo State, Nigeria \\ ${ }^{4}$ Department of Technical and Applied Physics, School of Physics and Earth Sciences Technology, Technical University of Kenya, \\ P.O. Box 52428-00200, Nairobi, Kenya \\ ${ }^{5}$ Department of Chemical Engineering, Faculty of Industrial Technology, Universitas Pembangunan Nasional Veteran Yogyakarta, \\ Sleman, Indonesia \\ ${ }^{6}$ Department of Chemistry, Faculty of Science and Technology, Airlangga University, Mulyorejo, Surabaya 60115, Indonesia \\ ${ }^{7}$ Department of Mechanical Engineering, Edo State University Uzairue, P.M.B. 04, Auchi, 312101 Edo State, Nigeria \\ ${ }^{8}$ Research Center for Biomaterials, Indonesian Institute of Sciences, Jl. Raya Bogor km 46, Cibinong, Bogor, \\ 16911 West Java, Indonesia
}

Correspondence should be addressed to Robert Birundu Onyancha; 08muma@gmail.com

Received 21 July 2021; Revised 16 August 2021; Accepted 25 August 2021; Published 9 September 2021

Academic Editor: Stefano Salvestrini

Copyright (C) 2021 Dyan Hatining Ayu Sudarni et al. This is an open access article distributed under the Creative Commons Attribution License, which permits unrestricted use, distribution, and reproduction in any medium, provided the original work is properly cited.

\begin{abstract}
Although several approaches have been explored for the removal of dyes and other toxic materials from water as well as the entire environment, notwithstanding, researchers/scientists are still pursuing novel, low-cost, and eco-friendly biosorbents for the effective removal of such contaminants. Herein, clove leaves (CL) were utilized as a biosorbent for the sequestration of malachite green (MG) from a water-soluble solution. The CL was subsequently activated using potassium hydroxide (KOH) and characterized using the FTIR and FESEM to determine the functional groups on the activated clove leaves (CL-KOH) and the morphology of the adsorbent. The adsorption of MG was observed to be relatively dependent on the dosage of sorbent utilized, initial MG concentration, and sorption process contact time. The adsorption process of MG to CL was ideally described using the Dubinin-Radushkevich and Elovich models with the determination of maximum sorption capacity of approximately $131.6 \mathrm{mg} \cdot \mathrm{g}^{-1}$. Furthermore, the thermodynamic parameters calculated showed that the adsorption of MG to the adsorbent was exothermic with the process involving physical sorption as well as chemical sorption processes with negligible adsorption energy. In conclusion, the study has revealed that the CL is a cost-effective biosorbent with high adsorption efficiency for the sequestration of MG from a water-soluble solution and can be recycled for further usage.
\end{abstract}

\section{Introduction}

The obliteration of the quality of water, soil, and air due to the fast-growing global population and industrialization is critical for life sustenance on earth. Water quality has exceptionally declined owing to the untreated effluents discharged into streams, oceans, and lakes, by the processes of mining, textile, paint and dye productions, and metal plating [1]. 
Among these noxious and aromatic contaminants released into water bodies devoid of the preceding appropriate treatment, the textile industry is a primary user of synthetic or noxious dyes for product colouring [2].

Dye is a major source of serious contamination owing to fast industrial development and extensive utilization [3]. Major consideration has been drawn by pollution of water by dye discharge from paper production, food processing, textile dyeing, paints, and cosmetic industries owing to community health and ecosystem hazards. At present, the worldwide colourant market is about 32 billion United States Dollars (USD) and is projected to grow to 42 billion USD in 2021. Yearly, the total of synthetic dyes manufactured is estimated to be over 700,000 tons, and over $15 \%$ of these synthetic colourants are yearly discharged into water. Water polluted by these dyes is noxious, xenobiotic, and carcinogenic, and they are grouped according to their chromophore structure into the solvent, reactive, basic, vat, and direct dyes. Exclusively, $47 \%$ of synthetic dyes are decomposable [4].

MG is a cationic dye and is positively (+ve) charged in a water-soluble solution. It has a three-benzene ring structure compound as shown in Figure 1, with a molecular formula of $\mathrm{C}_{23} \mathrm{H}_{25} \mathrm{CIN}_{2}$ and a molecular weight of $364.917 \mathrm{~g} / \mathrm{mol}$ [5, 6]. It is a synthetic triarylmethane dye and a natural compound utilized as a dyestuff and has appeared as a contentious agent in aquaculture as an ectoparasiticide and fungicide owing to its effectiveness and minimal cost. It is conventionally employed as a dye for materials like silk, wood, acrylic, paper, and leather. However, their intense colour causes a horrible colour to water bodies, and it is intractable to degrade by light and other oxidizing agents, heightening concerns for the environment and making its confiscation challenging. It is extremely noxious to animal cells, carcinogenic, and mutagenic and causes inflammation to the skin. Various health problems associated with the use of MG include a reduction in red blood cell (RBC) count (dyscrasia) and enhanced white blood cell count (leukocytosis), haemoglobin (anemia), and interruption of blood coagulation, eye blisters, wild breathing, and copious sweating. Also, associated with MG utilization is the impairment to the kidney, liver, spleen, and heart and infliction of lacerations on the skin, eyes, lungs, and bones which produces teratogenic impacts $[1,3,5,7]$. Therefore, there is an urgent need for the adaptation of eco-friendly approaches for the treatment of MG effluents before their release into water bodies and streams to safeguard the ecosystem [1].

Dye sequestration from water bodies has substantial importance to the ecosystem, and developing effective and cost-effective removal techniques is an ongoing and continuous effort. These methods comprise the adsorption of dye pollutants to mineral or carbon-based matrix [8], photocatalysis or oxidation processes [9], chemical precipitation [10], ion exchange [11], microbiological or enzymatic decomposition [12], coagulation [13], reverse osmosis [14], membrane filtration [15], biological treatment [16], etc.

Among these existing methods, adsorption is more efficient due to its effortlessness, operational ease, and the reality that it does not produce sludge, thus ensuring a safe environment [8]. The process of adsorption is a distinctive

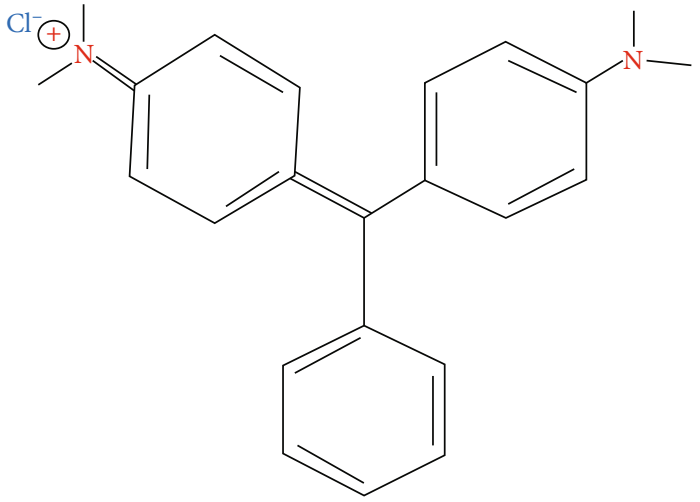

Figure 1: The molecular structure of MG was adopted and redrawn from [6].

technique for the confiscation of contaminants from watersoluble solutions by putting them precisely on the surface of the adsorbent [17]. Adsorption methods are more costeffective when compared to their substitutes if the adsorbent is local to the treatment area and needs no prior treatment before its application in the treatment of effluents. While various biosorbents such as sugarcane waste, neem sawdust, maize cob, Parthenium weed, jackfruit peel, freshwater algae, rice husks, fly ash, CL, and spent tea leaves have been employed for MG dye sequestration from aqueous solutions, the search for minimal cost waste materials for harmful dye removal from water-soluble solution before removal lingers. From a financial point of view, the utilization of these waste materials is crucial [5].

To confiscate various noxious metals, dyes, and contaminants, numerous nontraditional low-cost biosorbents from agriculture and forestry, plant biomass, and microorganisms are utilized. Agricultural leftover utilization as a biosorbent is due to the substantial benefit of easy application, minimal cost, no or low chemical utilization, and elevated efficiency $[18,19]$.

Syzygium aromaticum (L.) Merr. and L.M. Perry (Syn. Eugenia caryophyllus) are the Myrtaceae tree family, which are indigenous to Indonesia. The aromatic flower buds of this plant are known as cloves and are generally used as a spice. They are economically garnered in Madagascar, India, Pakistan, Sri Lanka, Indonesia, Seychelles, Tanzania, and Comoro Islands. In China and Western nations, they are employed as medicine against diseases like cough, diarrhoea, dyspepsia, flatulence, oral or dental diseases, nausea and vomiting, and stomach distension and for gastrointestinal spasm controls, pain relief, uterine contraction, and nerve stimulation. The essential oil resulting from this aromatic plant acts not only as a fragrance and flavour agent but also as dietary antioxidants in the prevention of various diseases caused by free radicals [20].

Cloves (Syzygium aromaticum) comprise a wide variety of bioactive compounds consisting of oleanolic acid, caryophyllene, eugenol, and eugenin. The active compounds in cloves have the potential and properties to perform antifungal, antimicrobial, antiseptic, antibacterial, anti-inflammatory, anticarcinogenic, and antihistaminic activities to inhibit recurring metabolic disorders and tumour cells $[21,22]$. 

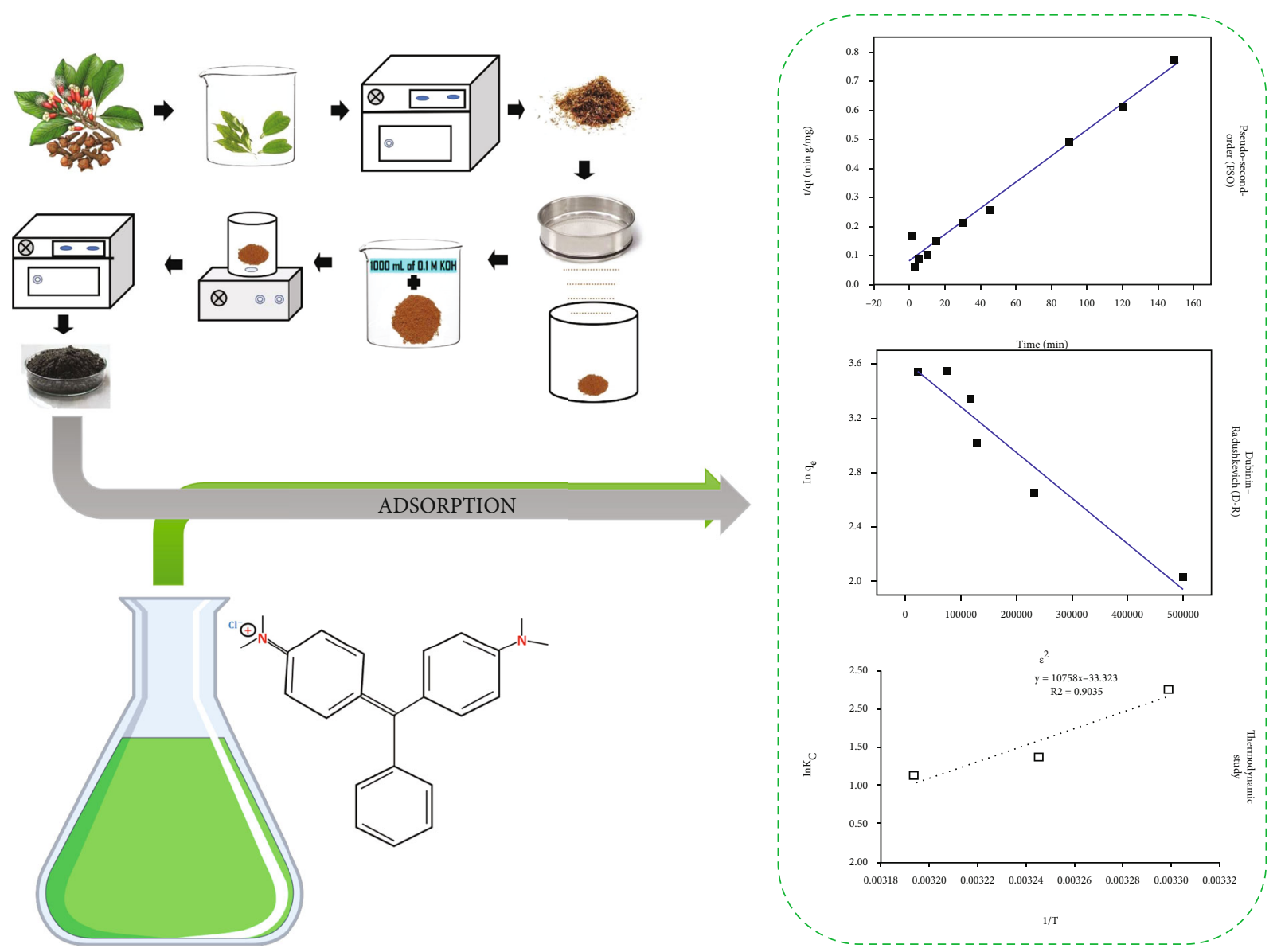

Figure 2: The outline of the study.
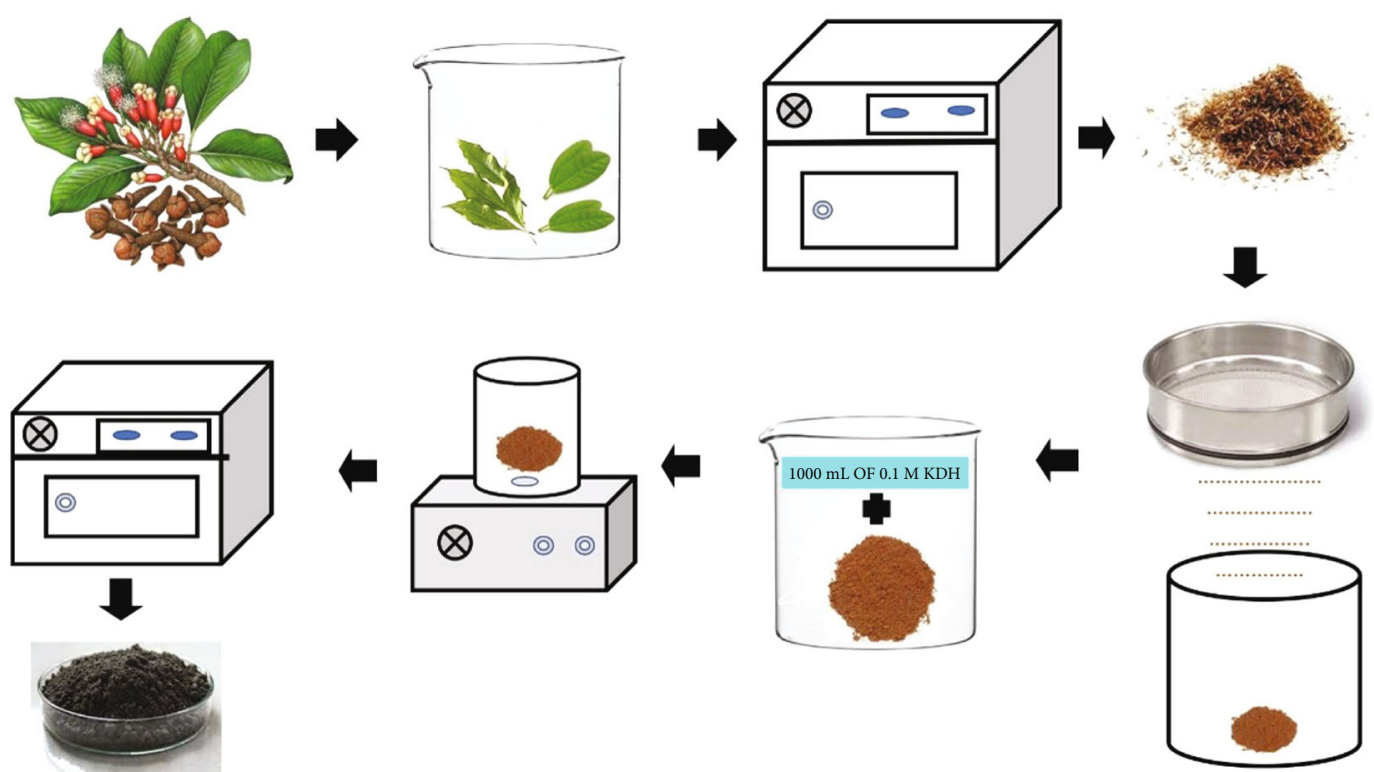

FIgure 3: Steps for the synthesis of CL-KOH biosorbent for this study.

Supposedly, there are some existing studies on the removal of MG. For example, Reference [23] investigated the concurrent ultrasound-assisted adsorption of two dyes (MG and safranin O) from aqueous solutions onto copper nanowires laden on activated carbon (Cu-NWs-AC) with results revealing that $0.022 \mathrm{~g}$ of $\mathrm{Cu}-\mathrm{NWs}-\mathrm{Ac}$ led to the removal of $15 \mathrm{mg} \cdot \mathrm{L}^{-1}$ of $\mathrm{MG}$ and $15 \mathrm{mg} \cdot \mathrm{L}^{-1}$ of safranin within $6 \mathrm{~min}$ at $\mathrm{pH}$ of 5.5 . Similarly, a study by [24] recently 


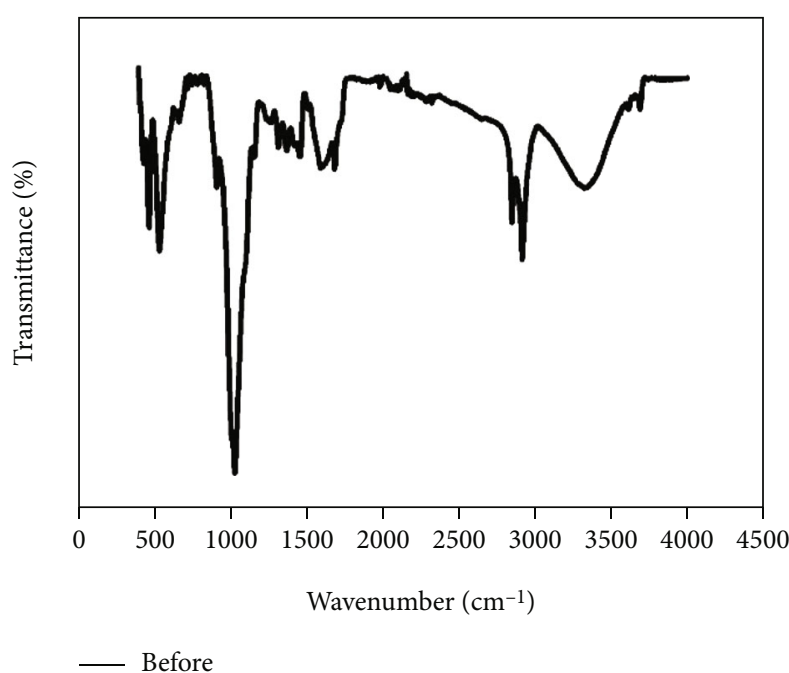

(a)

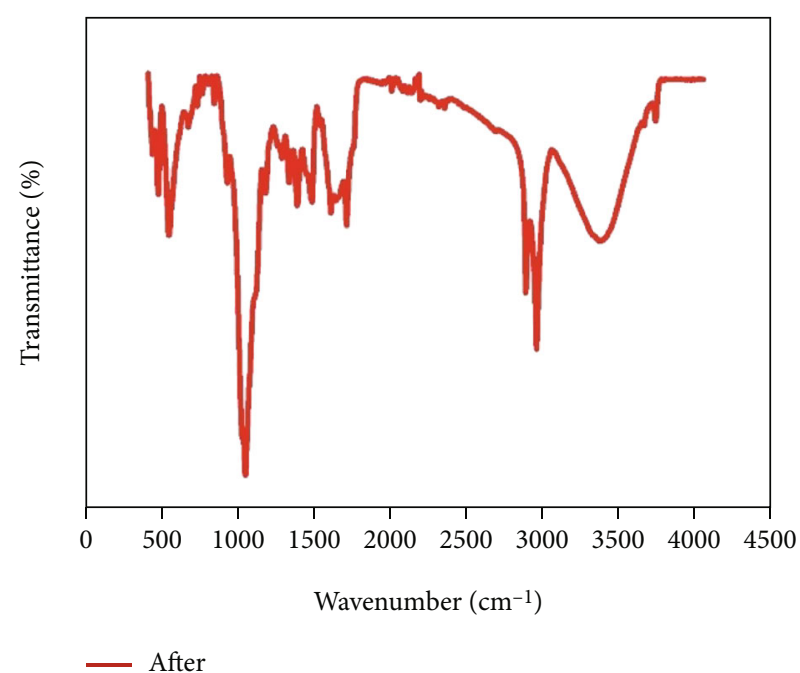

(b)

Figure 4: The FTIR spectra (a) prior to adsorption onto CL-KOH (b) following MG adsorption onto CL-KOH.

sequestered the Yarrowia lipolytica ISF7 strain with a distinctive capability which was employed for the removal of MG from culture. It was established that the maximum adsorption capacity occurred around the $\mathrm{pH}$ of 6.5-7.5, thus depicting a low removal percentage of dye in acidic $\mathrm{pH}$ below 5 and above 7.5 for an alkaline state. Furthermore, $\mathrm{Mn}$-doped CuO-nanoparticle- (NP-) activated carbon (AC) which was arranged via a simple technique and categorized employing various procedures for the adsorption of MG and methyl orange in some single and binary solutions was reported by [25]. The adsorption mechanism was well fitted with the Langmuir (LNR) model with a maximum adsorption capacity of $320.69 \mathrm{mg} \cdot \mathrm{g}^{-1}$ and $290.11 \mathrm{mg} \cdot \mathrm{g}^{-1}$ for a single solution while the binary solution gave $233.02 \mathrm{mg}^{-1} \mathrm{~g}^{-1}$ and $205.53 \mathrm{mg}^{-1} \mathrm{~g}^{-1}$ for MG and methyl orange, respectively.

There are also other reported removal procedures of dyes such as crystal violet and a brilliant green from wastewater using various biosorbents such as live yeast Yarrowia lipolytica 70562 [26]. Also, these various studies reported the effectiveness of confiscation of azure II and auramine O from aqueous solutions using Pinus eldarica stalk AC, while Congo red, phloxine B and fast green FCF, methylene blue dye, and basic red 46 were adsorbed onto $\mathrm{CuS} / \mathrm{ZnS}$ nanocomposites loaded on AC and polyvinyl alcohol/$\mathrm{Fe}_{3} \mathrm{O}_{4} @$ carbon nanotubes, and $\mathrm{Ce}$ doped on $\mathrm{TiO}_{2} \mathrm{NPs}$ which was loaded on AC as biosorbents was also explored and reported [27-30].

As reported in a recent review study by [31], there are several existing publications on the utilization of adsorbents for the elimination of dyes and heavy metals as well as other contaminants from wastewater and the environment at large. Notwithstanding, there is still a need for researchers/scientists to continue the pursuit of other novel and ecofriendly biosorbents for the effective removal of such contaminants. Under these recent situations, cheap and effective biosorbents are needed for the removal of dyes and other environmental contaminants. Hence, this present paper summarizes the exploration and application of biosorbent created from clove leaf $(\mathrm{CL})$ agrowaste activated using potassium hydroxide $(\mathrm{KOH})$ as a novel bioadsorbent with higher efficiency (removal capacity) as well as the cost-effectiveness trends for MG (Figure 2 shows an outline of the study).

From the research papers/publications reviewed, it is evident that there is a lack of adequate reports on utilizing/employing CL-KOH as a biosorbent for dye removal, particularly MG from water-soluble solutions; thus, this research will try to bridge the gap. Consequently, this work examines the feasibility of dye confiscation from water-soluble solution using CL synthesized at an elevated temperature and activated using $\mathrm{KOH}$. The $\mathrm{CL}-\mathrm{KOH}$ synthesized was characterized using various procedures such as Field Emission Scanning Electron Microscope (FESEM) and the Fourier Transform Infrared Spectroscopy (FTIR). Then, the adsorption studies were systematically examined by enhancing various adsorption parameters such as the adsorbent dosage, time of contact, and temperature as well as stirring rates. Finally, the results were fitted to isotherm, kinetic, and thermodynamic models.

\section{Experimental}

2.1. Materials and Methods. Analytical grade purified chemicals were used without further distillation. $\mathrm{KOH}$ and $\mathrm{MG}$ were purchased from UD, Sumber Ilmiah Persada, Surabaya, Indonesia.

2.2. Synthesis of Biosorbent. The CL (Syzygium aromaticum) utilized as a biosorbent for the sequestration of MG dye in this study were from the extract of CL oil waste obtained from the community-owned essential oil refineries, Madiun, East Java, Indonesia. The CL was initially washed carefully with distilled water (DW) and dried in an oven for 24 hours (hr) at $60^{\circ} \mathrm{C}$. The dried CL was then milled and sieved through a 60-mesh-size sieve. Afterwards, $25 \mathrm{~g}$ of the CL in powder form was measured and soaked in $1000 \mathrm{~mL}$ of $0.1 \mathrm{M} \mathrm{KOH}$ solution. The combination was further stirred 


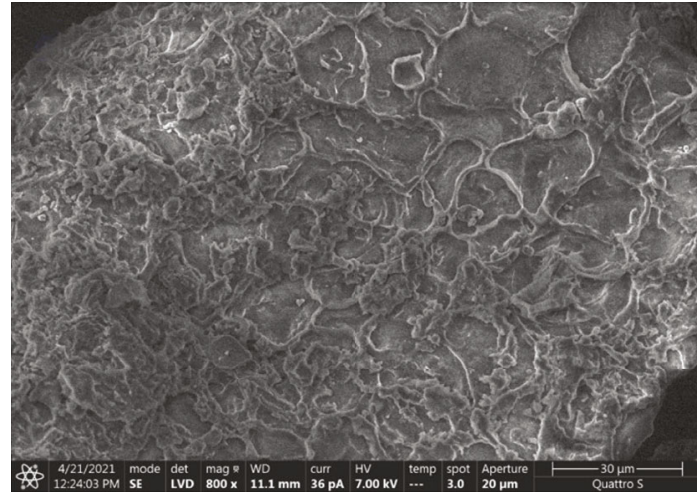

(a)

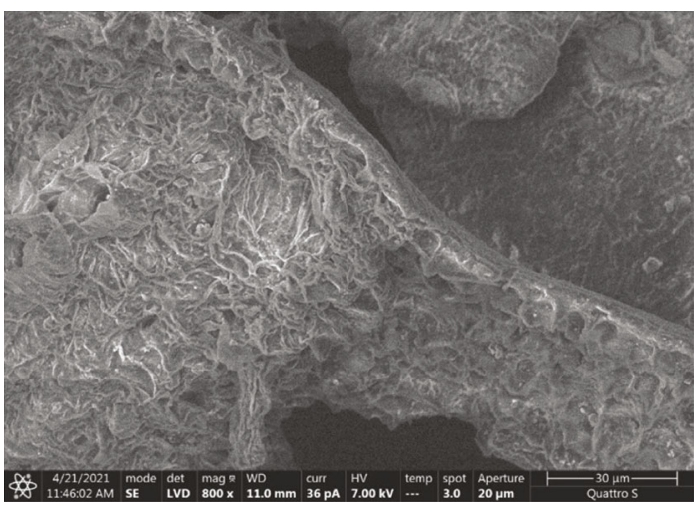

(b)

FIgURE 5: The SEM images of biosorbent (a) before adsorption of MG and (b) after adsorption of MG.

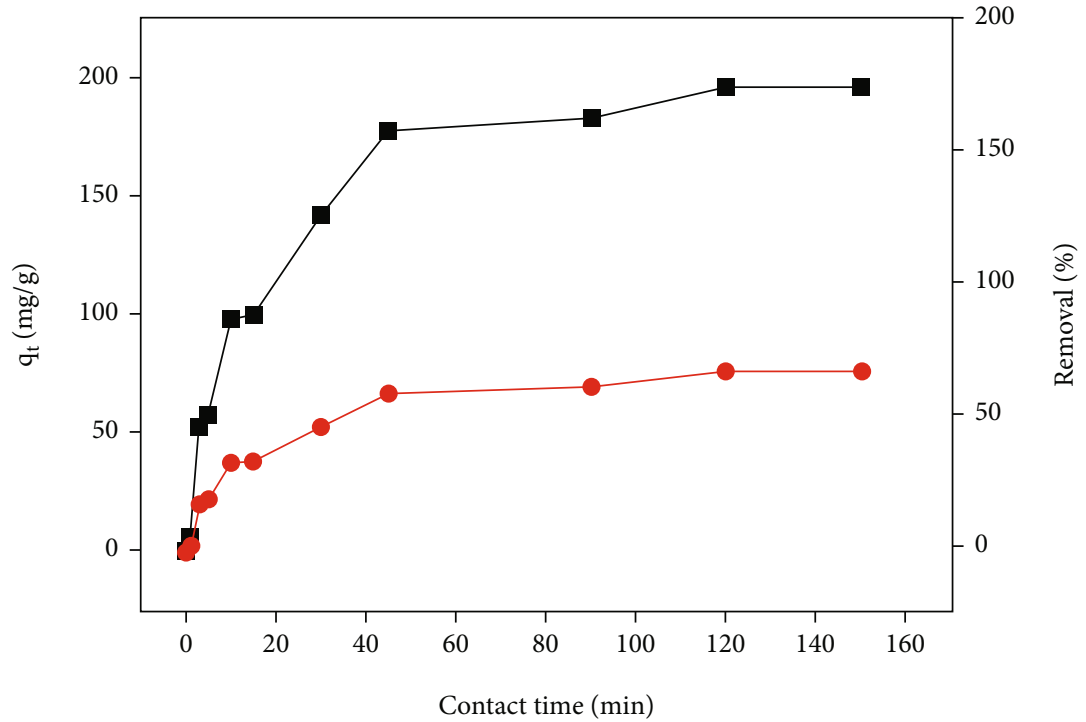

FIGURE 6: The contact time effect (condition: initial MG concentration $=0.03 \mathrm{mg} \cdot \mathrm{L}^{-1}$, dosage of adsorbent used $=0.15 \mathrm{~g} \cdot \mathrm{L}^{-1}$, temperature $=303.15 \mathrm{~K}$, and shaking speed $=200 \mathrm{rpm})$.

using a magnetic stirrer at a speed of $400 \mathrm{rpm}$ for $5 \mathrm{hr}$. The combination was subsequently filtered and washed with DW until the filtrate had a neutral $\mathrm{pH}$. The filtrate was airdried in a vacuum oven at $60^{\circ} \mathrm{C}$ for a day and stored in a desiccator before prior use for batch experiments. Figure 3 shows the steps employed for the preparation of the CL$\mathrm{KOH}$ biosorbent.

\subsection{Characterization of Biosorbent. The produced CL-KOH} biosorbents were characterized utilizing the FESEM (Thermo Scientific Quattro S) to determine the particle size and morphology of the prepared biosorbent. While the FTIR spectra of the biosorbent were obtained using PerkinElmer UATR at a range of $400-4000 \mathrm{~cm}^{-1}$ wavenumber.

2.4. Preparation of Stock Solution of MG. A $1000 \mathrm{mg} \cdot \mathrm{L}^{-1}$ of MG stock solution was produced by measuring $1 \mathrm{~g}$ of the adsorbate and dissolving it in DW $(1000 \mathrm{~mL})$ in a volumetric flask. To prepare appropriate initial MG concentrations of the adsorbate used for batch experiments, it was achieved by diluting the stock solution using DW.

2.5. Biosorption Batch Studies. The batch method was employed in this study to examine the uptake of MG from water-soluble solutions to $\mathrm{CL}-\mathrm{KOH}$. Determining the impact of the biosorbent dosage employed for the sequestration of MG was explored by contacting varying amounts of the biosorbent of $0.5-3.0 \mathrm{~g} / \mathrm{L}$ at a constant temperature of $303.15 \mathrm{~K}$, shaking speed of $200 \mathrm{rpm}$, initial MG concentration of $0.03 \mathrm{mg} / \mathrm{L}, \mathrm{pH}$ value of 6 , and contact time of 150 min. Determining the equilibrium concentration of MG after adsorption using the adsorbent was evaluated from a calibration curve using the GENESYS 10S UV/Vis spectrophotometer at a $617 \mathrm{~nm}$ wavelength. The removal efficiency of the CL was evaluated by computing the percentage removal using

$$
\text { \%removal }=\frac{C_{\mathrm{ic}}-C_{\mathrm{ec}}}{C_{\mathrm{ec}}} \times 100,
$$




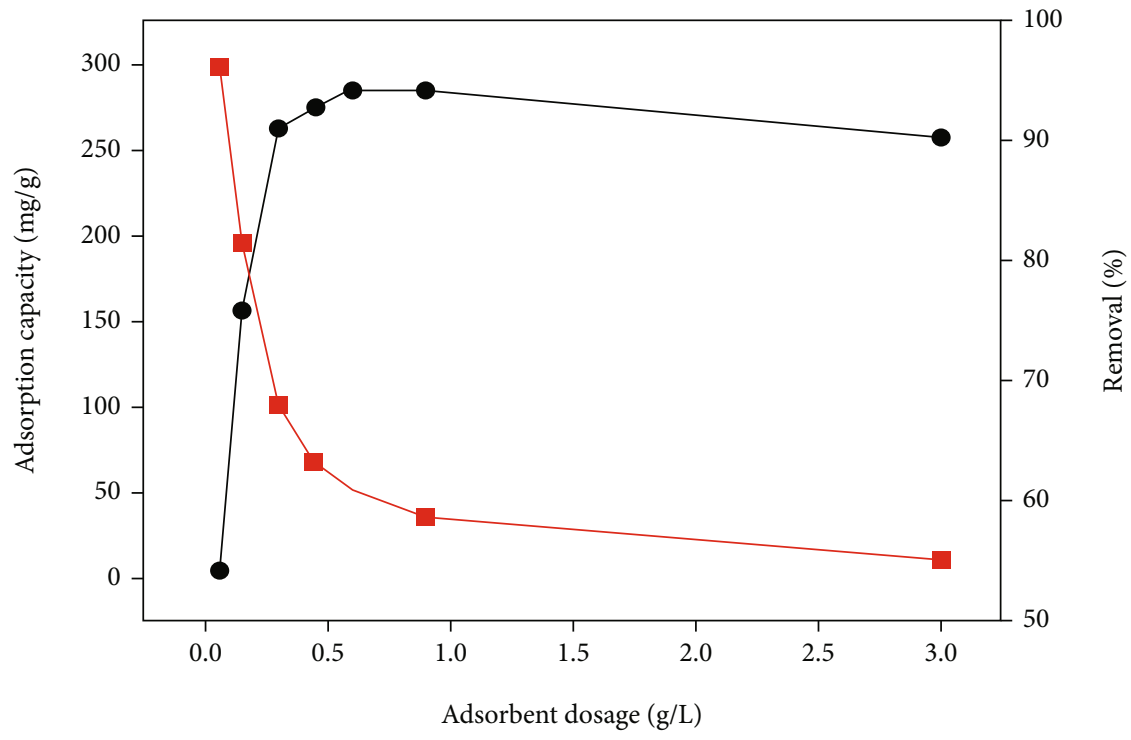

Figure 7: The impact of dosage of adsorbent employed in this study (condition: initial MG concentration $=0.03 \mathrm{mg} \cdot \mathrm{L}^{-1}$, contact time $=$ $150 \mathrm{~min}$, temperature $=303.15 \mathrm{~K}$, and shaking speed $=200 \mathrm{rpm})$.

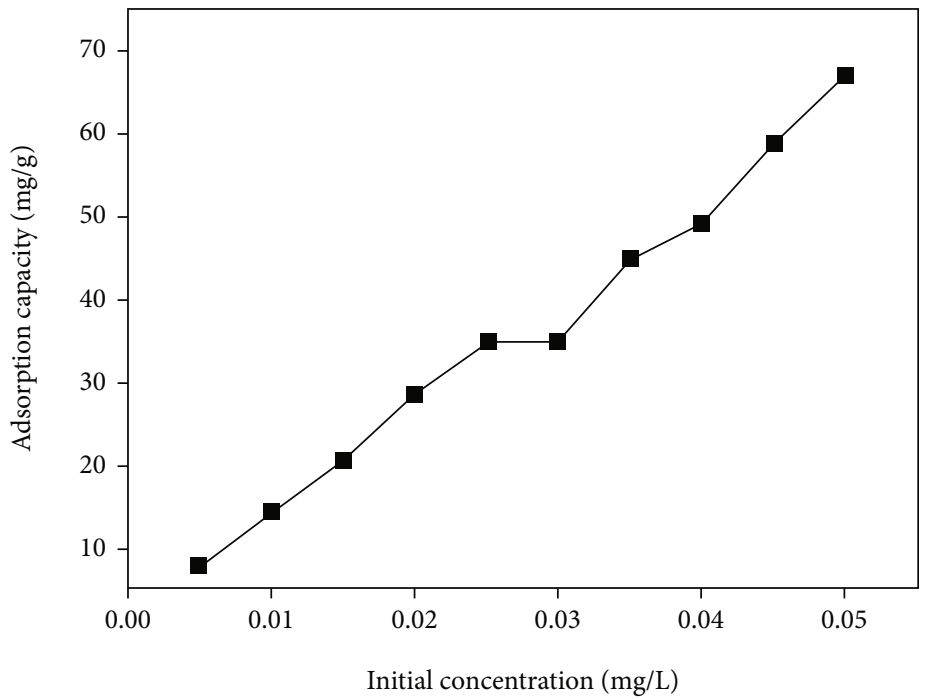

FIGURE 8: The effect of initial concentration of MG (condition: the dosage of adsorbent used $=0.90 \mathrm{~g} \cdot \mathrm{L}^{-1}$, contact time $=150 \mathrm{~min}$, temperature $=303.15 \mathrm{~K}$, and shaking speed $=200 \mathrm{rpm}$ ).

where $C_{\mathrm{ic}}$ and $C_{\mathrm{ec}}$ signify the initial and equilibrium concentrations of $\mathrm{MG}(\mathrm{mg} / \mathrm{L})$.

To explore the effect of the contact time on the adsorption of MG to the biosorbent, $0.03 \mathrm{mg} \cdot \mathrm{L}^{-1}$ of $\mathrm{MG}$ was treated with $0.015 \mathrm{~g} / \mathrm{L}$ of the adsorbent at a temperature of $303.15 \mathrm{~K}$, shaking speed of $200 \mathrm{rpm}$, and $\mathrm{pH}$ at 6 and under varying contact times of 0-160 min. The time-dependent quantity of the MG sorbed by a unit mass of CL at varying contact times was determined using

$$
q_{\mathrm{t}}=\frac{C_{\mathrm{ic}}-C_{\mathrm{t}}}{W} \times V
$$

$q_{\mathrm{t}}, C_{\mathrm{t}}, V$, and $m$ indicate the time-dependent amount of MG sorbed per unit of adsorbent mass $\left(\mathrm{mg}^{-1} \mathrm{~g}^{-1}\right.$ ), the bulk phase concentration $\left(\mathrm{mg} \cdot \mathrm{L}^{-1}\right)$ at any time $t$, the sample volume (L), and the dosage of sorbent employed (g).

The impact of initial MG concentrations and the adsorption isotherm was determined by contacting $0.9 \mathrm{~g} / \mathrm{L}$ of the adsorbent with varying initial MG concentrations of 0.005 $0.05 \mathrm{mg} / \mathrm{L}$ at a temperature of $303.15 \mathrm{~K}, \mathrm{pH} 6$, sorption process time of contact of $150 \mathrm{~min}$, and shaking speed of $200 \mathrm{rpm}$. The equilibrium sorption capacity $\left(q_{\mathrm{e}}\right)$ was determined using

$$
q_{\mathrm{e}}=\frac{C_{\mathrm{ic}}-C_{\mathrm{ce}}}{W} \times V
$$

2.6. Desorption and Regeneration. To clarify the nature of the adsorption process and assess the possibility to recover the 
TABLE 1: The sorption kinetic models employed for this study.

\begin{tabular}{lccr}
\hline Kinetic models & Equations & Parameters & Values \\
\hline PFO & $\ln \left(q_{e}-q_{t}\right)=\ln q_{e}-k_{1} t$ & $k_{1}\left(\mathrm{~min}^{-1}\right)$ & 0.0427 \\
PSO-type 1 & $\frac{t}{q_{t}}=\frac{1}{k_{2} q_{e}^{2}}+\frac{t}{q_{e}}$ & $R^{2}$ & 0.9631 \\
& & $k_{2}\left(\mathrm{~g}(\mathrm{mg} \cdot \mathrm{min})^{-1}\right)(\mathrm{type} \mathrm{1)}$ & 0.0003 \\
PSO-type 4 & $k_{2}\left(\mathrm{~g}(\mathrm{mg} \cdot \mathrm{min})^{-1}\right)(\mathrm{type} 4)$ & 0.00009 \\
& & $R^{2}(\mathrm{type} \mathrm{1)}$ & 0.9824 \\
PSO-type 4 & $k_{2}\left(\mathrm{~g}(\mathrm{mg} \cdot \mathrm{min})^{-1}\right)(\mathrm{type} 4)$ & 0.00009 \\
& $\frac{q_{t}}{t}=K_{2} q_{e}^{2}-\frac{K_{2} q_{t}^{2}}{q_{e}}$ & $R^{2}(\mathrm{type})$ & 0.07585 \\
& & $K_{w}\left(\mathrm{mg} \cdot \mathrm{g}^{-1} \cdot \mathrm{min}^{-1 / 2}\right)$ & 16.6700 \\
Intraparticle diffusion & $q_{t}=K_{W} t^{1 / 2}+C$ & $R^{2}$ & 23.3920 \\
& & $a_{e}\left(\mathrm{mg}\left(\mathrm{g} \cdot \mathrm{min}^{-1}\right)\right.$ & 0.8912 \\
Elovich & $b_{e}\left(\mathrm{~g} \cdot \mathrm{mg}^{-1}\right)$ & 43.8815 \\
& $q_{t}=\frac{R^{2}\left(a_{e} b_{e}\right)}{b_{e}}+\frac{1}{b_{e}} \ln t$ & 0.0250 \\
\end{tabular}

sorbate and regenerate/recycle the biosorbent, desorption experiments were performed on the CL- $\mathrm{KOH}$ with preadsorbed MG dye using $0.1 \mathrm{M} \mathrm{NaOH}$ and $\mathrm{HCI}$ to treat MG of the $0.03 \mathrm{mg} / \mathrm{L}$ concentration dye for a time duration of one hour at a shaking speed of $200 \mathrm{rpm}$ on a magnetic stirrer. After desorption, the biosorbents were isolated from the MG solution by centrifugation at $4000 \mathrm{rpm}$ for $10 \mathrm{~min}$, and the supernatant solution was analyzed using the UVvis spectrophotometer. The percentage efficiency was determined using

$$
\text { Efficiency }(\%)=\frac{\text { Uptake in the second run }}{\text { Uptake in the first run }} \times 100 \text {. }
$$

\section{Results and Discussions}

3.1. Biosorbent Characterization. Figure 4 depicts the FTIR spectra of $\mathrm{CL}-\mathrm{KOH}$ before and the adsorption of MG obtained at a wavenumber range of $400-4000 \mathrm{~cm}^{-1}$. The characteristic FTIR peaks appearing at 3333.43, 2866.21, $1686.53,1594.05, \quad 1456.36,1316.37-1030.96,1240.75$, 912.14, and $433.13-535.95 \mathrm{~cm}^{-1}$ were due to hydroxyl stretching vibration, asymmetrical patterns of group $\mathrm{CH}_{2}$ of the alcoholic group in the essential oil, $\mathrm{C}=\mathrm{C}$ stretching vibration of an aromatic moiety of eugenol, $\mathrm{C}-\mathrm{C}$ aromatic ring vibrations of eugenol acetate, $-\mathrm{C}=\mathrm{C}, \mathrm{C}-\mathrm{O}$ vibrations of ether and alcohol functional group of eugenol and eugenol acetate, $\mathrm{C}-\mathrm{O}-\mathrm{C}$ symmetric expansion of aromatic acid esters and $\mathrm{C}-\mathrm{OH}$ vibrational stretching of phenolic compounds, bending vibration absorption of $\mathrm{C}-\mathrm{H}$ groups, and $\mathrm{C}-\mathrm{C}$ of the amine group (Figure 4(a)) [32-35]. After the adsorption of MG to the adsorption, there was a redshift of most of the functional groups with FTIR peak values of 3334.26, 2850.11, $1605,48,1687.16,1463.02,1314.96-1031-03,1268.15,912.03$, and $429.10-534.92 \mathrm{~cm}^{-1}$ (Figure $4(\mathrm{~b})$ ). The wavelength shift demonstrated that a dye-binding process took place at the surface of the biosorbent.
The FESEM images of the biosorbent prior to and subsequently after adsorption are shown in Figures 5(a) and 5(b). A porous, rough, and irregular surface morphology is observed. It was observed that there was no significant difference in the biosorbent surface form before and after the biosorption of MG. Images show clearly the action of biosorption on the surface morphology of the biosorbent, which showed a decreased pore size of the biosorbent owing to $M G$ impregnation onto the surface of the adsorbent.

3.2. The Contact Time Effect on the Adsorption of MG to CL$\mathrm{KOH}$. The adsorption of MG to CL-KOH at various contact times is displayed in Figure 6. It was noticed that the sorption capacity was improved with an upsurge in the time of contact for the sorption process and that equilibrium was attained after $120 \mathrm{~min}$ for MG. At low MG concentrations, the sorbent surface area available to the ratio of the initial MG concentration was higher than that of the adsorbate molecules at low concentration, leading to improved adsorption capacity. Also, the high driving force of the mass of adsorbent transfer at high concentrations leads to an expansion in the sorption capacity as the initial MG concentration is enhanced $[8,19]$.

3.3. The Impact of Dosage of Adsorbent Used on the Sorption of $M G$ to $C L-K O H$. The sum of active sites accessible and ions exchanged for sorption varies with the number of adsorbent sites in the biosorption process [36]. It was noticed in Figure 7 that the percentage of MG removed onto the adsorbent increased with increasing adsorbent dosage. At a low adsorbent dosage, there were insufficient active sorption sites to inhabit by the adsorbate and while at a high adsorbent dosage, there were sufficient sorption sites for occupancy by the adsorbate. The increase in the percentage of MG removed was attributed to the enhanced amount of active sites accessible and the enhanced surface area. Above the dosage of $0.6 \mathrm{~g} / \mathrm{L}$ that adsorbents used, no further 


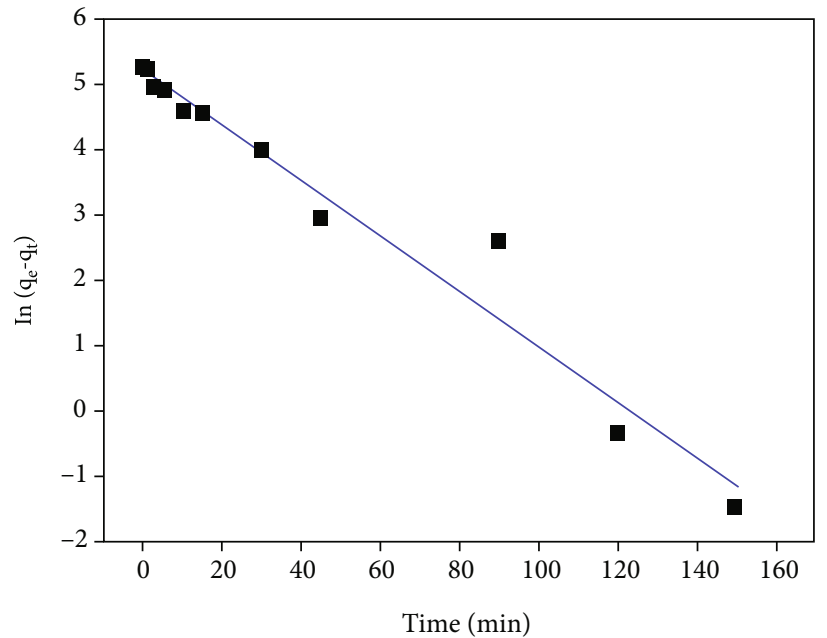

(a)

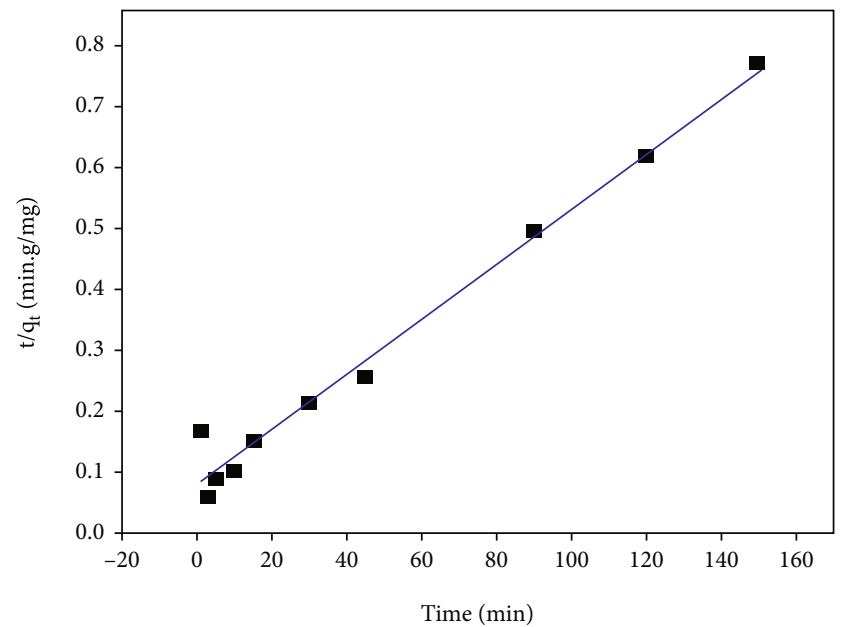

(b)

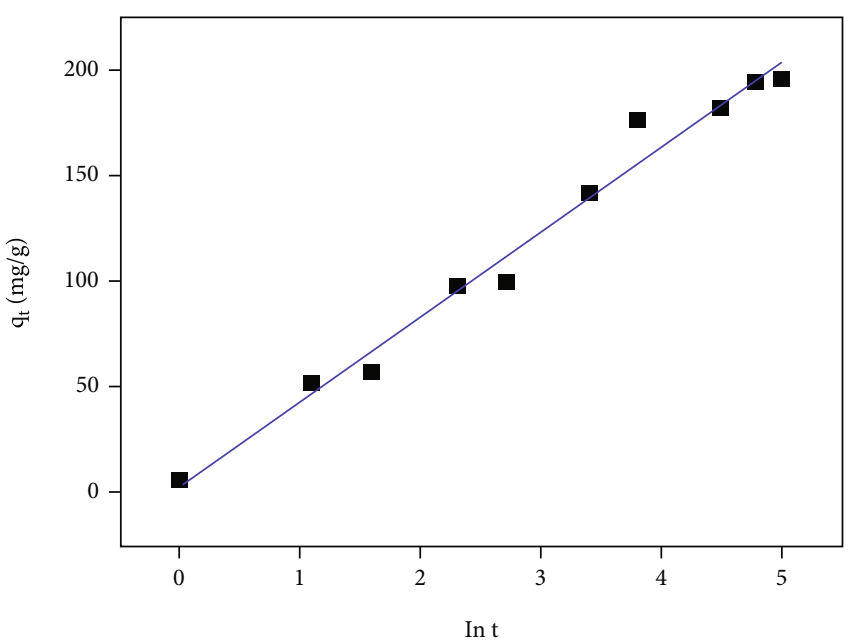

(d)

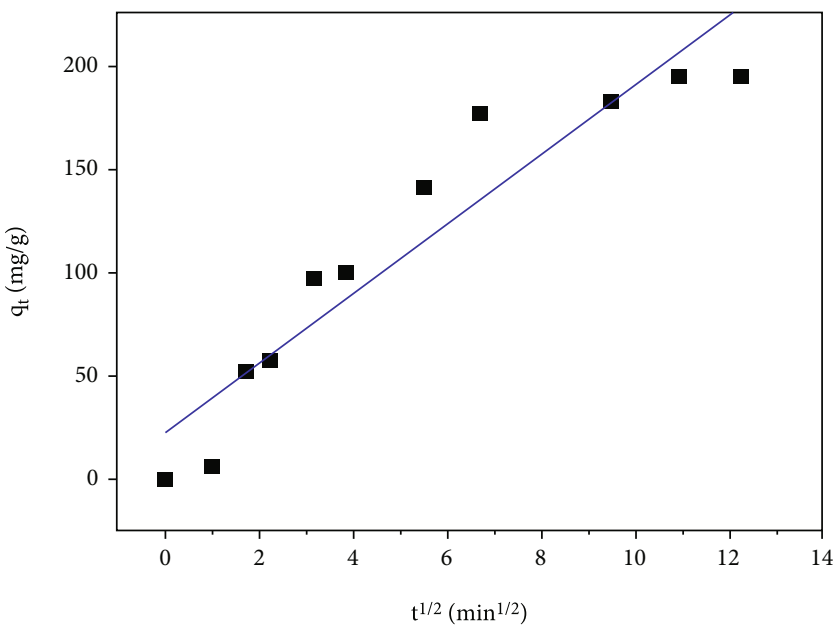

(c)

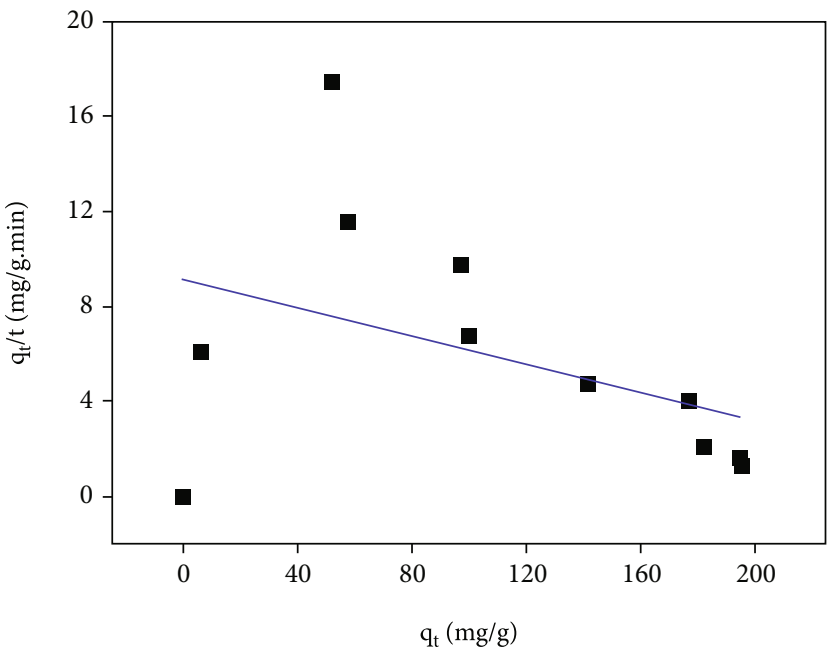

(e)

FIgure 9: The plots of (a) PFO, (b) PSO (type 1), (c) intraparticle diffusion, and (d) Elovich and PSO (type 4) models.

remarkable change was observed in the removal percentage of MG and was ascribed to the overlapping of the active sites in the biosorbent. Also, with regard to the extent of adsor- bate sorbed at equilibrium, the sorption capacity decreased with increasing adsorbent dosage due to the split in the concentration rise between the surface of the adsorbent and the 
TABLE 2: The sorption isotherm models employed for this study.

\begin{tabular}{lccc}
\hline $\begin{array}{l}\text { Isotherm } \\
\text { models }\end{array}$ & Equations & $\begin{array}{c}\text { Parameter } \\
\text { dimensions }\end{array}$ & Values \\
\hline \multirow{2}{*}{ LNR } & $\frac{C_{e}}{q_{e}}=\frac{1}{b Q_{m}}+\frac{C_{e}}{Q_{m}}$ & $Q_{m}$ & 131.5789 \\
& & $R^{2}$ & 0.0275 \\
& & $K_{F}$ & 0.1567 \\
FRH & $\ln q_{e}=\ln K_{F}+\frac{1}{n} \ln C_{e}$ & $n$ & 1.3108 \\
& & $R^{2}$ & 0.8117 \\
& & $B$ & 18.3300 \\
TMN & $q_{e}=B \ln K_{t}+B \ln C_{e}$ & $K_{t}$ & 0.5354 \\
& & $R^{2}$ & 0.8318 \\
& & $q_{s}$ & 37.7808 \\
D-R & $\ln q_{e}=\ln q_{s}-K_{D-R} \varepsilon^{2}$ & $K_{D-R}$ & 0.000003 \\
& & $E$ & 408.2483 \\
& & $R^{2}$ & 0.9332 \\
\hline
\end{tabular}

solution [37]. The reduction in the sorption capacity with enhanced biosorbent dosage at a constant dye concentration and volume will lead to the unsaturation of a specific number of the active sites on the biosorbent. Also, the decrease of the sorption capacity may be associated with the particle aggregation resulting from increased biosorbent dosage. Such aggregation will result in reduced total surface area and improved diffusion path length to be travelled by the sorbate inside the biosorbent $[38,39]$.

3.4. The Impact of Initial MG Concentration on the Adsorption Process. The effect of the initial MG concentration sorption onto the CL activated using $\mathrm{KOH}$ was examined by setting a time of adsorption contact of $150 \mathrm{~min}$ and $\mathrm{pH}$ value of 6 , and the dosage of the adsorbent used was $0.09 \mathrm{~g} / \mathrm{L}$. With an intensification in the initial MG concentration, the sorption capacity was observed to be enhanced (Figure 8). The biosorbent sorption capacity improved from 7.675 to $67.102 \mathrm{mg} \cdot \mathrm{g}^{-1}$ by increasing the initial MG concentration from 0.005 to $0.05 \mathrm{mg} \cdot \mathrm{L}^{-1}$. This increase was ascribed to the high collision between the molecules of the adsorbate (MG) and the active adsorbent sites, hence improving the driving force of the adsorbate to the adsorbent surface [40].

3.5. Kinetic Studies. Various adsorption processes occur via a multistep mechanism which includes the dispersion across the liquid film bordering the particle of a solid (an external mass transfer coefficient controls this process), the dispersion within the individual particles assumes a mechanism of pore diffusion (intraparticle diffusion), and the chemical and physical sorption occurs at a sorption site. The transitory behaviour of a batch sorption process at various temperatures and initial adsorbate concentrations is generally studied using the Lagergren first-order (also called pseudofirst-order, PFO) and the pseudo-second-order (PSO) models [41]. Kinetic research is generally employed by several scientists to examine the mechanism of the sorption process taking place. Preexisting models are applied in most sorption kinetic research, and this acts as a guide in demonstrating the mechanism of sorption. An extensive range of standard models exists to rationalize the sorption at various requirements, and the most appropriate is selected for the provided experimental terms. The linearized forms and calculated parameters of each kinetic model are presented in Table 1 [42]. The various linear plots of the individual kinetic model are displayed in Figure 9. From each model plot, the rate constants and the calculated correlation coefficients $\left(R^{2}\right)$ are provided in Table 1 . The correlation coefficient of the PSO model gave a superior explanation of MG sorption to CL-KOH $\left(R^{2}=0.9824\right)$ when compared to other kinetic models $\left(R^{2}-\mathrm{PFO}=0.9631\right.$, intraparticle diffusion $=$ 0.8912 , and Elovich $=0.9804)$.

The least-square technique was utilized for finding the parameters for kinetic models. The fourth form of the linearized forms of the PSO model simple linear regression could result in various parameter estimates as observed from the fourth form of the PSO model [43]. Results using this type 4 PSO model are shown in Table 1. It was observed from Figure 9(e) that the data substantially deviated from linearity. Hence, the PSO model could not intensively describe the trend of the experimental data, which was confirmed by the low value of the coefficient of correlation $\left(R^{2}=0.07585\right)$. The $R^{2}$ obtained employing the PSO kinetic model of type 4 is remarkably lower than those obtained employing type 1. But this model (type 1 PSO model) may lead to incorrect conclusions mostly when the sorption data are at (or very close to) equilibrium, and in such cases, the type 1 plot becomes linear irrespective of the sorption kinetics [44]. The kinetic of MG dye sorption to the biosorbent was governed by the Elovich model, with chemisorption rate $\left(a_{\mathrm{e}}\right)$ and surface coverage $\left(b_{\mathrm{e}}\right)$ constants of $43.8815 \mathrm{mg}(\mathrm{g} \cdot \mathrm{min})^{-1}$ and $0.0250 \mathrm{~g} \cdot \mathrm{mg}^{-1}$, respectively. The equilibrium sorption capacity uptake was $222.222 \mathrm{mg} / \mathrm{g}$ for the linear PSO model. Therefore, the experimental value of the sorption capacity fitted well with the theoretical sorption capacity values evaluated from the PSO model.

3.6. Isotherm Studies. The association between the solute equilibrium concentration in the adsorbent and the solute equilibrium concentration in the solution at a steady temperature is defined by the isotherm [34]. Selecting the ideal model of isotherm for the process of sorption, the resulting conditions must be satisfied: (i) the model of the isotherm and the determined equilibrium data must have a superlative fit, (ii) the isotherm function must be thermodynamically accurate, and (iii) in ideal situations, the systematic calculation of concentration is from the capacity and the other way around [42]. The sorption equilibrium data in this study was assessed using the LNR, Freundlich (FRH), Temkin (TMN), and D-B isotherm models.

The earliest far-famed equation which described the sorption technique was the FRH model. It is linked with an empirical equation and employed for a nonideal natural process that comprises heterogeneous surface sorption. The 


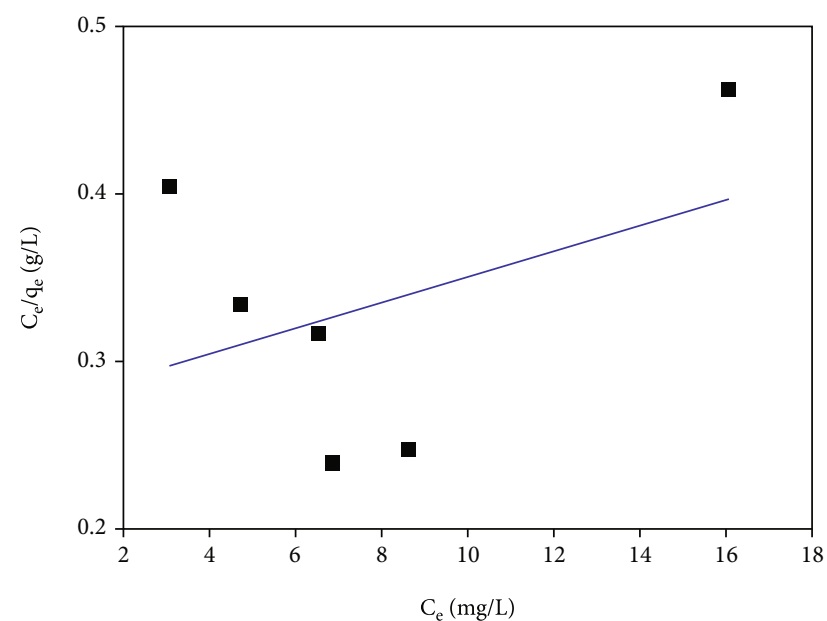

(a)

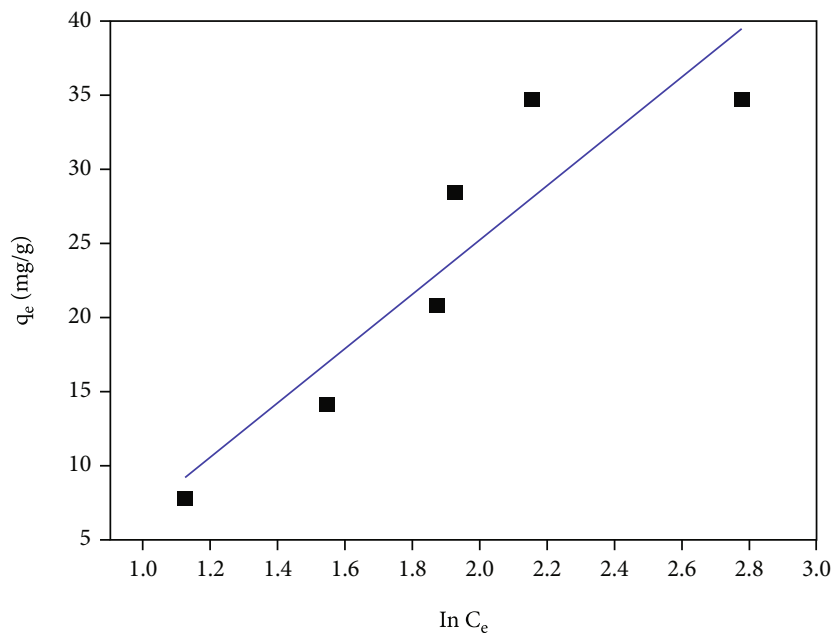

(c)

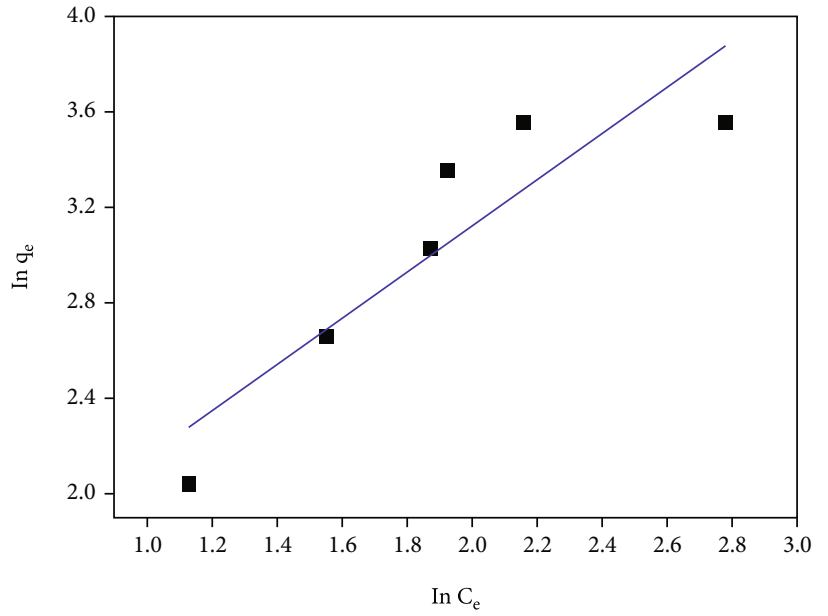

(b)

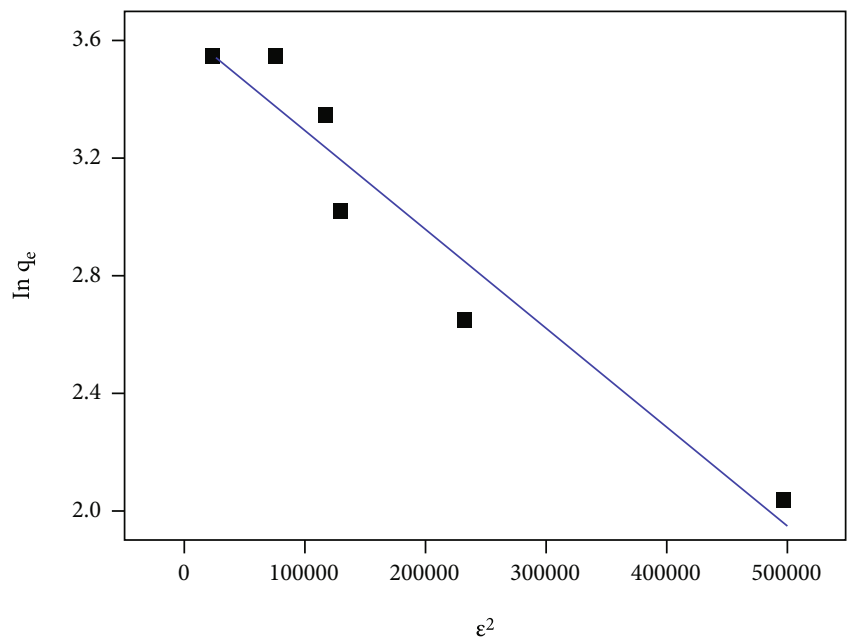

(d)

FIgURE 10: The sorption of MG to CL-KOH using (a) LNR, (b) FRH, (c) TMN, and (d) D-R isotherm models.

TABLE 3: The comparison of sorption capacity of CL-KOH with other described/reported biosorbents on MG.

\begin{tabular}{lcc}
\hline Biosorbents & $Q_{m}(\mathrm{mg} / \mathrm{g})$ & References \\
\hline Typha australis at $21.4^{\circ} \mathrm{C}$ & 85.21 & {$[50]$} \\
Baker's yeast- $\mathrm{MnO}_{2}$ composites & 243.90 & 5.620 \\
AC of khat (Catha edulis) & 12.00 & {$[51]$} \\
Activated rice husks & 714.30 and 1250.00 & {$[53]$} \\
Untreated and treated oil palm empty fruit bunch & 39.683 & {$[54]$} \\
Coconut shell derived $\mathrm{ZnCl}_{2} \mathrm{AC}$ & 320.69 (single solution) and 233.02 (binary solution) \\
Mn-doped CuO-NPs loaded on AC & 35.00 & {$[25]$} \\
Yarrowia lipolytica ISF7 strain $25^{\circ} \mathrm{C}$ & 15.00 & {$[24]$} \\
Copper nanowires loaded on AC & 131.5789 & This study \\
CL-KOH & &
\end{tabular}

FRH model's expression is given in Table 2, where $K_{\mathrm{f}}$ and $n$ are FRH constants representing the sorption capacity and the sorption intensity, respectively [45]. The LNR model is employed to define the sorption of the adsorbate by presuming that the monolayer sorption ensues on a similar surface without the sorbed ions interacting [19].
The TMN model predicts that the energy of sorption is reduced linearly with the surface coverage owing to the interaction between the adsorbent and adsorbate. Sorption is considered by the bonding energies up to the optimum binding energy regular distribution [46], while the D-R model predicts that the sorption is multilayered and 


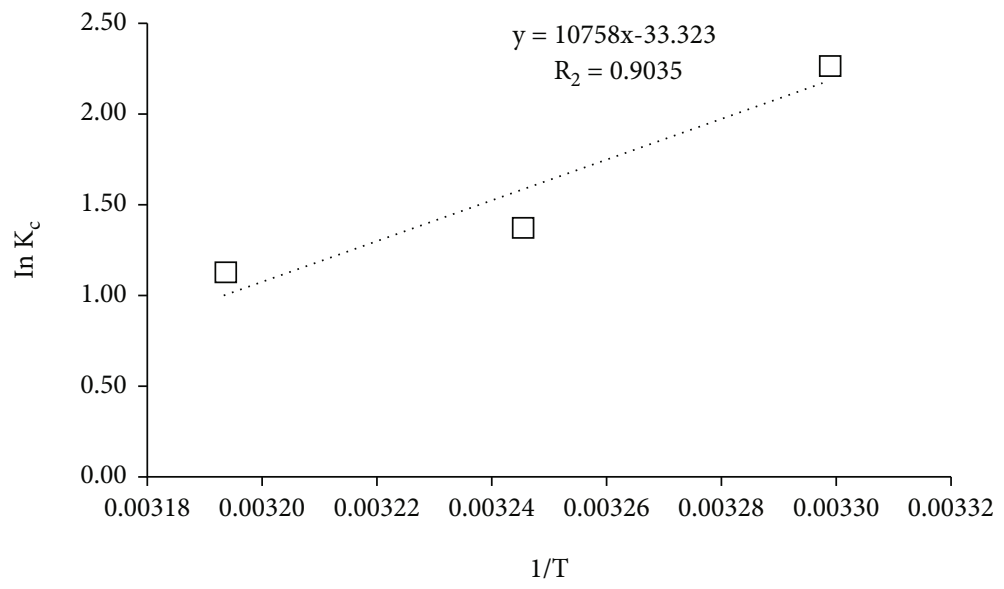

FIgURE 11: The plot of In $K_{\mathrm{c}}$ against $1 / T$ was employed to determine the thermodynamic study parameters.

TABLE 4: The thermodynamic parameters for this study.

\begin{tabular}{lccc}
\hline$T(\mathrm{~K})$ & $\Delta G^{\mathrm{o}}\left(\mathrm{kJ} \cdot \mathrm{mol}^{-1}\right)$ & $\Delta H^{\mathrm{o}}\left(\mathrm{kJ} \cdot \mathrm{mol}^{-1}\right)$ & $\Delta S^{\mathrm{o}}\left(\mathrm{kJ} \cdot \mathrm{mol}^{-1}\right)$ \\
\hline 303.15 & -5.4551 & & \\
308.15 & -4.0699 & -8.9442 & -0.2771 \\
313.15 & -2.6846 & & \\
\hline
\end{tabular}

comprises the van der Waals forces which are related to the processes of physical sorption [47]. The linearized forms of the models are illustrated in Table 2.

The various plots for each isotherm using their linearized forms are shown in Figure 10, and based on their correlation coefficient values for all models, the highest calculated correlation coefficient value was for the D-R model, which was 0.9332 when compared to other models (LNR -0.1567, FRH -0.8117, and TMN -0.8318). The magnitude of $E$ gives valuable evidence on the mechanism of adsorption like physical adsorption $(E<8 \mathrm{~kJ} / \mathrm{mol})$, ion exchange $(8<E<16 \mathrm{~kJ} / \mathrm{mol})$, and chemical adsorption $(E>16 \mathrm{~kJ} / \mathrm{mol})$ [48, 49]. The sorption energy $(E)$ obtained from the D-R model $\left(408.2483 \mathrm{~kJ} \cdot \mathrm{mol}^{-1}\right)$ was greater than $16 \mathrm{~kJ} / \mathrm{mol}$. From the D-R results reported in this study, the sorption process of MG to CL- $\mathrm{KOH}$ was a result of the chemisorption process. The maximum sorption capacity values of various biosorbents for the removal of $M G$ as described/reported in various publications compared with the present study result are shown in Table 3. It can be observed that the maximum sorption capacity of CL-KOH as biosorbents for the removal of MG $\left(131.6 \mathrm{mg}^{-1} \mathrm{~g}^{-1}\right)$ is among the highest values obtained in MG studies reported.

3.7. Thermodynamic Studies. The assessment of the three key thermodynamic parameters (change in enthalpy $\left(\Delta H^{\circ}\right)$, Gibbs free energy change $\left(\Delta G^{\circ}\right)$, and entropy change $\left(\Delta S^{\circ}\right)$ are employed to explain the conditions of thermodynamic sorption. The net change in enthalpy is associated with $\Delta$ $G^{\circ}$ and $\Delta S^{\circ}$ as $\Delta G=\Delta H-T(\Delta S)$, and the slope and intercept of the plot of In $K_{\mathrm{c}}$ vs. $1 / T$ are used to also determine $\Delta S^{\circ}$ (Figure 11) [55, 56]. The determined thermodynamic parameters for the sorption of MG to CL-KOH are given in Table 4. The negative value of $\Delta G^{\circ}$ for the interaction of

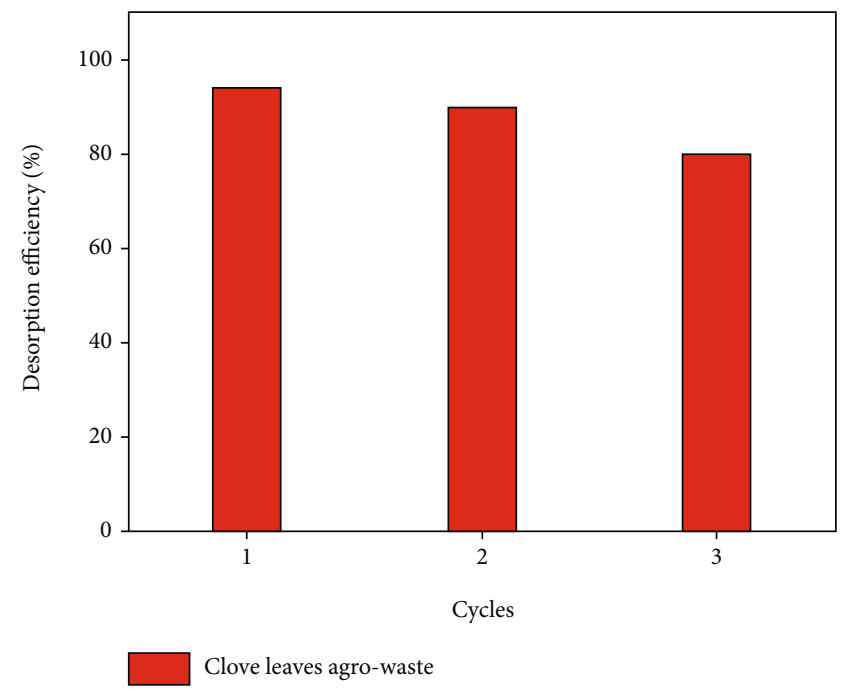

FIGURE 12: The cycles of adsorption-desorption of MG.

MG with the adsorbent at all temperatures showed that the interaction was spontaneous in standard conditions and thermodynamically promising and reasonable [57]. The respective decrease in the $\Delta G^{\circ}$ value from -5.4551 to $-2.6846 \mathrm{~kJ} / \mathrm{mol}$ with intensification in temperature (303.15$313.15 \mathrm{~K})$ observed was due to physical process $\left(\Delta G^{\circ}\right.$ values between -20 and $0 \mathrm{~kJ} / \mathrm{mol}$ ) [48]. The negative value of $\Delta H^{\circ}$ indicated an exothermic in nature interaction between $\mathrm{MG}$ and the CL-KOH which reinforced that the reduction in sorption capacity increases with temperature due to heat being released to the system; the equilibrium changes are in parallel direction to the reaction. The value of $\Delta H^{\circ}$ was $<40 \mathrm{~kJ} / \mathrm{mol}$, which was suggestive that a physisorption process was involved in the sorption of MG to CL-KOH [48, 58]. While the negative values for $\Delta S^{\circ}$ were indicative of the degree of nonrandomness of the sequestration of $M G$ to the adsorbent, which corresponds to the sorbed species degree of freedom [59], which reinforced that the reduction in sorption capacity increases with temperature due to heat being released to the system, the equilibrium changes are in parallel direction to the reaction. 


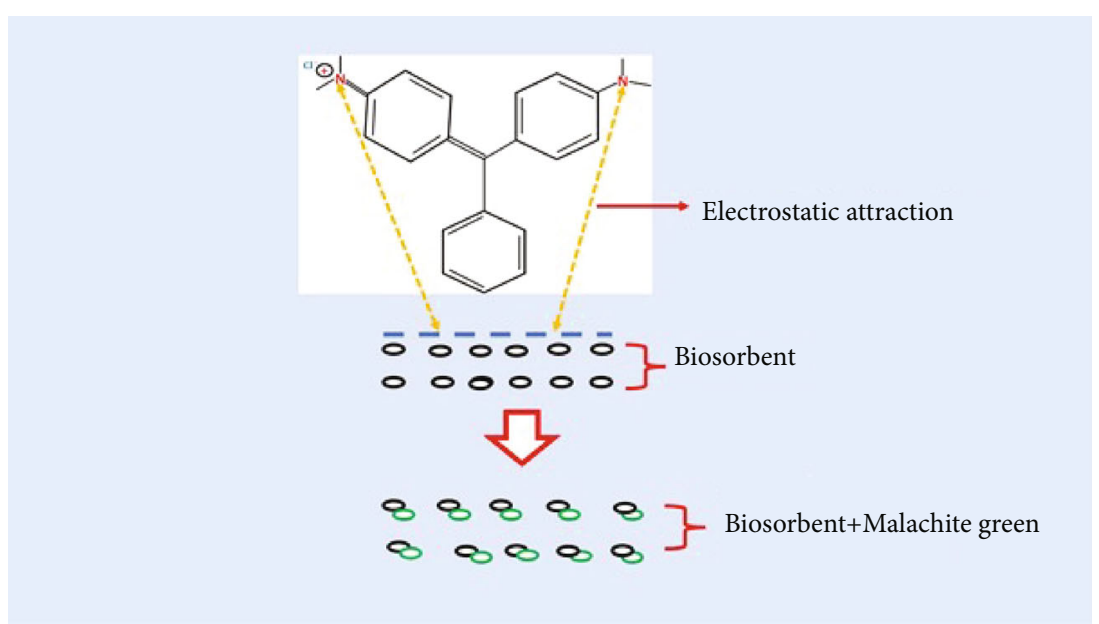

FIgURE 13: Proposed mechanism of MG adsorption to the biosorbent.

3.8. Desorption and Regeneration. Extreme desorption efficiency and excellent reusability after sorption are required for a sorbent; hence, the desorption studies are essential to describe the nature of sorption and evaluate the spent sorbent and dye recycling [60]. The desorption and regeneration processes of the spent biosorbent using $0.1 \mathrm{M}$ of $\mathrm{NaOH}$ and $\mathrm{HCl}$ are shown in Figure 12. It was observed that $0.1 \mathrm{M} \mathrm{NaOH}$ was more effective in the regeneration of the biosorbent when compared to $0.1 \mathrm{M} \mathrm{HCl}$. Three cycles of adsorption-desorption were carried with a maximum desorption efficiency of $94 \%$ and a minimum desorption efficiency of $80 \%$ observed in the first and last cycles. Hence, the CL-KOH biosorbent showed excellent sorption performance and regeneration, and its utilization can be extended to environmental applications for effluent treatment.

3.9. Proposed Mechanism of Adsorption of $M G$ to the Biosorbent. The selection of the most promising biosorbent types from an exceptionally sizeable collection of freely accessible materials is a major task for the adsorption field. The subsequent real task is the recognition of the mechanism of adsorption [61]. The biosorption of MG to the biosorbent (CL-KOH) was sturdily dependent on different polar functional groups on the sorbent surface like hydroxyl, phenol, amine, carboxyl, and aromatic groups which are supported by the FTIR spectra in Figure 4. As observed from Figure 4, there was a small shift in the FTIR spectral position and a change in its intensity. Various active functional groups that show essential impacts on the sorption of MG were on the surface of lignin, pectin, cellulose, and hemicellulose. These results were indicative of the binding of the MG dye to potential active accessible sites of the functional groups like hydroxyl, amine, $\mathrm{C}=\mathrm{O}, \mathrm{C}=\mathrm{C}, \mathrm{C}-\mathrm{O}, \mathrm{C}-\mathrm{C}, \mathrm{C}-\mathrm{O}-$ $\mathrm{C}$, and phenols via a weak electrostatic interaction or van der Waals forces, $\pi-\pi$ interaction, $n-\pi$ interaction, and hydrogen bonding $[62,63]$. These functional groups cause the intake of positively charged molecules of MG to the biosorbents. These were observed in the sorption of MG to lowcost Gibto (Lupinus albus) seed peel waste and AC of Catha edulis stem, as these sorbent surface functional groups may be neutral upon protonation or deprotonation and charged and multiple bonded upon delocalization $[52,60]$. The possible or proposed mechanism of the MG dye to the biosorbent surface through electrostatic attraction is depicted in Figure 13.

\section{Conclusion}

In this study, the ability of CL-KOH to confiscate MG from water-soluble solutions was investigated. Working parameters like initial MG concentration, adsorbent dosage, and contact time were determined to affect the sorption efficiency of CL-KOH. The D-R isotherm and Elovich kinetic models were found to ideally explain the sorption process of $\mathrm{MG}$ to $\mathrm{CL}-\mathrm{KOH}$ and the established recorded sorption capacity was $131.5789 \mathrm{mg} \cdot \mathrm{g}^{-1}$. Also, the adsorption of $\mathrm{MG}$ to $\mathrm{CL}-\mathrm{KOH}$ was found to be exothermic. The main mechanism of MG sorption to the biosorbent was attributed to chemisorption and physisorption processes according to results from the D-R isotherm and thermodynamic parameters. The present study shows that the synthesized CL-KOH biosorbent could be applied as an efficient and inexpensive adsorbent for the sequestration of dye molecules from industrial dye effluents and the treatment of real wastewater contaminated with MG. Consequently, this recent study has further demonstrated the use of CL- $\mathrm{KOH}$ as an effective biosorbent for the removal of dyes, and it can be recycled/regenerated and reused, thus lowering operational costs and safeguarding the environment. Therefore, recommendations on further research studies and progression towards enhancing adsorption capacity should be encouraged.

\section{Data Availability}

Completely, the data produced or investigated during this work are involved in this submitted article.

\section{Conflicts of Interest}

There is no conflict whatsoever to declare. 


\section{Acknowledgments}

The authors are honestly appreciative of their respective institutions.

\section{References}

[1] R. Sangeetha piriya, R. Jayabalakrishnan, M. Maheswari, K. Boomiraj, and S. Oumabady, "Coconut shell derived $\mathrm{ZnCl}_{2}$ activated carbon for malachite green dye removal," Water Science and Technology, vol. 83, no. 5, pp. 1167-1182, 2021.

[2] C. Ali, T. Peng, T. Ye, and I. Naz, "Sorption of cationic malachite green dye on phytogenic magnetic nanoparticles functionalized by 3-marcaptopropanic acid," RSC Advances, vol. 8, no. 16, pp. 8878-8897, 2018.

[3] E. Femila, R. Srimathi, and C. Deivasigamani, "Removal of malachite green using silver nanoparticles via adsorption and catalytic degradation," International Journal of Pharmacy and Pharmaceutical Sciences, vol. 6, pp. 579-583, 2014.

[4] H. Anwer, A. Mahmood, J. Lee, K. Kim, J. Park, and A. Yip, "Photocatalysts for degradation of dyes in industrial effluents: opportunities and challenges," Nano Research, vol. 12, no. 5, pp. 955-972, 2019.

[5] M. Amin, A. Alazba, and M. Shafiq, "Nonspontaneous and multilayer adsorption of malachite green dye by Acacia nilotica waste with dominance of physisorption," Water Science and Technology, vol. 76, no. 7, pp. 1805-1815, 2017.

[6] M. Das and C. Mishra, "Jackfruit leaf as an adsorbent of malachite green: recovery and reuse of the dye," SN Applied Sciences, vol. 1, no. 5, pp. 1-8, 2019.

[7] E. Oyelude, J. Awudza, and S. Twumasi, "Removal of malachite green from aqueous solution using pulverized teak leaf litter: equilibrium, kinetic and thermodynamic studies," Chemistry Central Journal, vol. 12, no. 1, pp. 81-110, 2018.

[8] U. Aigbe, M. H. W. Khenfouch, W. H. Ho, A. Maity, V. S. Vallabhapurapu, and N. M. Hemmaragala, "Congo red dye removal under the influence of rotating magnetic field by polypyrrole magnetic nanocomposite," Desalination and Water Treatment, vol. 131, pp. 328-342, 2018.

[9] O. Ama, A. Wilson, and S. Ray, "Photoelectrochemical degradation of methylene blue dye under visible light irradiation using EG/Ag- $\mathrm{ZrO}_{2}$ nanocomposite electrodes," International Journal of Electrochemical Science, vol. 14, pp. 9982-10001, 2019.

[10] U. Aigbe, R. Das, W. Ho, V. Srinivasu, and A. Maity, "A novel method for removal of $\mathrm{Cr}(\mathrm{VI})$ using polypyrrole magnetic nanocomposite in the presence of unsteady magnetic fields," Separation and Purification Technology, vol. 194, pp. 377387, 2018.

[11] U. Aigbe and O. Osibote, "A review of hexavalent chromium removal from aqueous solutions by sorption technique using nanomaterials," Journal of Environmental Chemical Engineering, vol. 8, no. 6, article 104503, 2020.

[12] N. Mohanan, Z. Montazer, P. Sharma, and D. Levin, "Microbial and enzymatic degradation of synthetic plastics," Frontiers in Microbiology, vol. 11, 2020.

[13] U. Aigbe, W. Ho, A. Maity, M. Khenfouch, and V. Srinivasu, "Removal of hexavalent chromium from wastewater using $\mathrm{PPy} / \mathrm{Fe} 3 \mathrm{O} 4 \mathrm{magnetic}$ nanocomposite influenced by rotating magnetic field from two pole three-phase induction motor," Journal of Physics: Conference Series, vol. 984, article 012008, 2018.
[14] R. Onyancha, U. Aigbe, K. Ukhurebor, and P. Muchiri, "Facile synthesis and applications of carbon nanotubes in heavy-metal remediation and biomedical fields: A comprehensive review," Journal of Molecular Structure, vol. 1238, article 130462, 2021.

[15] K. Ukhurebor, U. Aigbe, R. Onyancha et al., "Effect of hexavalent chromium on the environment and removal techniques: a review," Journal of Environmental Management, vol. 280, article 111809, 2021.

[16] X. Wang, J. Ni, S. Pang, and Y. Li, "Removal of malachite green from aqueous solutions by electrocoagulation/peanut shell adsorption coupling in a batch system," Water Science and Technology, vol. 75, no. 8, pp. 1830-1838, 2017.

[17] U. Aigbe, R. Onyancha, K. Ukhurebor, and K. Obodo, "Removal of fluoride ions using a polypyrrole magnetic nanocomposite influenced by a rotating magnetic field," RSC Advances, vol. 10, no. 1, pp. 595-609, 2019.

[18] D. Srinivasan and K. Ilavenil, "Biosorption of heavy metals and dyes using plant weeds-a review," International Journal of ChemTech Research, vol. 10, no. 7, 2017.

[19] V. Dinh, T. D. T. Huynh, H. M. le et al., "Insight into the adsorption mechanisms of methylene blue and chromium(iii) from aqueous solution onto pomelo fruit peel," RSC Advances, vol. 9, no. 44, pp. 25847-25860, 2019.

[20] A. Mbaveng and V. Kuete, "Syzygium aromaticum," in medicinal spices and vegetables from Africa, Academic Press, 2017.

[21] J. Gao, K. Mamouni, L. Zhang, and B. Lokeshwar, "Spice up your food for cancer prevention: cancer chemo-prevention by natural compounds from common dietary spices," in Evolutionary Diversity as a Source for Anticancer Molecules, pp. 275-308, Academic Press, 2021.

[22] S. Pulikottil and S. Nath, "Potential of clove of Syzygium aromaticum in development of a therapeutic agent for periodontal disease: a review," South African Dental Journal, vol. 70, no. 3, pp. 108-115, 2015.

[23] M. Roosta, M. Ghaedi, and A. Asfaram, "Simultaneous ultrasonic-assisted removal of malachite green and safranin O by copper nanowires loaded on activated carbon: central composite design optimization," RSC Advances, vol. 5, no. 70, pp. 57021-57029, 2015.

[24] A. Asfaram, M. Ghaedi, G. Ghezelbash et al., "Biosorption of malachite green by novel biosorbent Yarrowia lipolytica isf7 : Application of response surface methodology," Journal of Molecular Liquids, vol. 214, pp. 249-258, 2016.

[25] E. Sharifpour, E. Alipanahpour Dil, A. Asfaram, M. Ghaedi, and A. Goudarzi, "Optimizing adsorptive removal of malachite green and methyl orange dyes from simulated wastewater by $\mathrm{Mn}$-doped $\mathrm{CuO}$-nanoparticles loaded on activated carbon using CCD-RSM: mechanism, regeneration, isotherm, kinetic, and thermodynamic studies," Applied Organometallic Chemistry, vol. 33, no. 3, article e4768, 2019.

[26] E. Dil, M. Ghaedi, G. Ghezelbash, and A. Asfaram, "Multiresponses optimization of simultaneous biosorption of cationic dyes by live yeast Yarrowia lipolytica 70562 from binary solution: application of first order derivative spectrophotometry," Ecotoxicology and Environmental Safety, vol. 139, pp. 158-164, 2017.

[27] M. Jafari, M. Rahimi, M. Ghaedi, H. Javadian, and A. Asfaram, "Fixed-bed column performances of azure-II and auramine-O adsorption by Pinus eldarica stalks activated carbon and its composite with zno nanoparticles: Optimization by response surface methodology based on central composite design," 
Journal of Colloid and Interface Science, vol. 507, pp. 172-189, 2017.

[28] J. Pooralhossini, M. Ghaedi, M. Zanjanchi, and A. Asfaram, "Ultrasonically assisted removal of Congo red, phloxine B and fast green FCF in ternary mixture using novel nanocomposite following their simultaneous analysis by derivative spectrophotometry," Ultrasonics Sonochemistry, vol. 37, pp. 452463, 2017.

[29] F. Sadeghfar, M. Ghaedi, A. Asfaram, R. Jannesar, H. Javadian, and V. Pezeshkpour, "Polyvinyl alcohol/ $/ \mathrm{Fe}_{3} \mathrm{O}_{4} @$ carbon nanotubes nanocomposite: Electrochemical-assisted synthesis, physicochemical characterization, optical properties, cytotoxicity effects and ultrasound- assisted treatment of aqueous based organic compound," Journal of Industrial and Engineering Chemistry, vol. 65, pp. 349-362, 2018.

[30] E. Alipanahpour Dil, M. Ghaedi, A. Asfaram, F. Mehrabi, A. Bazrafshan, and L. Tayebi, "Synthesis and application of Ce-doped $\mathrm{TiO}_{2}$ nanoparticles loaded on activated carbon for ultrasound-assisted adsorption of basic red 46 dye," Ultrasonics Sonochemistry, vol. 58, article 104702, 2019.

[31] U. Aigbe, K. Ukhurebor, R. Onyancha, O. Osibote, H. Darmokoesoemo, and H. Kusuma, "Fly ash-based adsorbent for adsorption of heavy metals and dyes from aqueous solution: a review," Journal of Materials Research and Technology, vol. 14, pp. 2751-2774, 2021.

[32] K. Mohammed, H. Abdulkadhim, and S. Noori, "Chemical composition and anti-bacterial effects of clove (Syzygium aromaticum) flowers," International Journal of Current Microbiology and Applied Sciences, vol. 5, no. 2, pp. 483-489, 2016.

[33] K. Taraj, A. Andoni, Y. Fatos et al., "Spectroscopic investigation of Syzygium aromaticum L. oil by water distillation extraction," Journal of International Environmental Application and Science, vol. 15, no. 2, pp. 122-126, 2020.

[34] M. Alam, M. Aslam, and S. Rais, "Adsorption of zinc (II) and nickel (II) from aqueous solution using Syzygium aromaticum (cloves): kinetic and isotherm studies," Rasayan Journal of Chemistry, vol. 2, pp. 791-806, 2009.

[35] R. Yadav and K. Balasubramanian, "Polyacrylonitrile/Syzygium aromaticum hierarchical hydrophilic nanocomposite as a carrier for antibacterial drug delivery systems," RSC Advances, vol. 5, no. 5, pp. 3291-3298, 2015.

[36] S. Gupta and A. Kumar, "Removal of nickel (II) from aqueous solution by biosorption on A. barbadensis Miller waste leaves powder," Applied Water Science, vol. 9, no. 4, pp. 1-11, 2019.

[37] T. Roy and N. Mondal, "Biosorption of Congo red from aqueous solution onto burned root of Eichhornia crassipes biomass," Applied Water Science, vol. 7, no. 4, pp. 1841-1854, 2017.

[38] F. Silva, L. Nascimento, M. Brito, K. da Silva, W. Paschoal, and R. Fujiyama, "Biosorption of methylene blue dye using natural biosorbents made from weeds," Materials, vol. 12, no. 15, p. 2486, 2019.

[39] N. Cardoso, R. Pinto, E. Lima et al., "Removal of remazol black B textile dye from aqueous solution by adsorption," Desalination, vol. 269, no. 1-3, pp. 92-103, 2011.

[40] S. Fiyadh, M. AlOmar, W. Binti Jaafar et al., "Artificial neural network approach for modelling of mercury ions removal from water using functionalized CNTs with deep eutectic solvent," International Journal of Molecular Sciences, vol. 20, no. 17, p. 4206, 2019.

[41] F. Boudrahem, F. Aissani-Benissad, and A. Soualah, "Adsorption of Lead(II) from aqueous solution by using leaves of date trees as an adsorbent," Journal of Chemical \& Engineering Data, vol. 56, no. 5, pp. 1804-1812, 2011.

[42] P. Srivatsav, B. Bhargav, V. Shanmugasundaram, J. Arun, K. Gopinath, and A. Bhatnagar, "Biochar as an eco-friendly and economical adsorbent for the removal of colorants (Dyes) from aqueous environment: a review," Water, vol. 12, no. 12, p. $3561,2020$.

[43] I. Oboh, E. Aluyor, and T. Audu, "Second-order kinetic model for the adsorption of divalent metal ions on Sida acuta leaves," International Journal of Physical Sciences, vol. 8, no. 34, pp. 1722-1728, 2013.

[44] S. Salvestrini, P. Vanore, A. Bogush, S. Mayadevi, and L. Campos, "Sorption of metaldehyde using granular activated carbon," Journal of Water Reuse and Desalination, vol. 7, no. 3, pp. 280-287, 2017.

[45] K. Abuthahir, C. Pragathiswaran, P. Govindhan, B. Abbubakkar, and V. Sridevi, "Adsorption of methylene blue dye using activated carbon from the natural plant stem," International Journal of Research in Pharmacy and Chemistry, vol. 7, no. 1, pp. 120-125, 2017.

[46] J. Wang, G. Liu, T. Li, and C. Zhou, "Physicochemical studies toward the removal of $\mathrm{Zn}$ (II) and $\mathrm{Pb}$ (II) ions through adsorption on montmorillonite-supported zero-valent iron nanoparticles," RSC Advances, vol. 5, no. 38, pp. 2985929871, 2015.

[47] J. Mbugua, P. Guto, V. Madadi, and G. Kamau, "Modeling of experimental adsorption isotherm data for chlorothalonil by Nairobi river sediment," International Journal of Scientific \& Technology Research, vol. 3, pp. 259-268, 2017.

[48] H. Tran, S. You, and H. Chao, "Thermodynamic parameters of cadmium adsorption onto orange peel calculated from various methods: a comparison study," Journal of Environmental Chemical Engineering, vol. 4, no. 3, pp. 2671-2682, 2016.

[49] M. Mahmoud, "Kinetics and thermodynamics of aluminum oxide nanopowder as adsorbent for Fe (III) from aqueous solution," Beni-Suef University Journal of Basic and Applied Sciences, vol. 4, no. 2, pp. 142-149, 2015.

[50] A. N'diaye, Y. Ali, O. Abdallahi et al., "Sorption of malachite green from aqueous solution using Typha australis leaves as a low cost sorbent," Journal of Environmental Treatment Techniques, vol. 8, no. 3, pp. 1023-1028, 2020.

[51] B. Santos, A. Cossolin, H. Reis et al., "Baker's yeast- $\mathrm{MnO}_{2}$ composites as biosorbent for malachite green: an ecofriendly approach for dye removal from aqueous solution," Revista Ambiente \& Água, vol. 14, no. 1, 2019.

[52] G. Abate, A. Alene, A. Habte, and D. Getahun, "Adsorptive removal of malachite green dye from aqueous solution onto activated carbon of Catha edulis stem as a low cost bio-adsorbent," Environmental Systems Research, vol. 9, no. 1, pp. 1-13, 2020.

[53] S. Chowdhury, R. Mishra, P. Saha, and P. Kushwaha, "Adsorption thermodynamics, kinetics and isosteric heat of adsorption of malachite green onto chemically modified rice husk," Desalination, vol. 265, no. 1-3, pp. 159-168, 2011.

[54] R. Mustapha, A. Ali, G. Subramaniam et al., "Removal of malachite green dye using oil palm empty fruit bunch as a low-cost adsorbent," Biointerface Research in Applied Chemistry, vol. 11, no. 6, pp. 14998-15008, 2021.

[55] H. Tutu, E. Bakatula, S. Dlamini, E. Rosenberg, V. Kailasam, and E. M. Cukrowska, "Kinetic, equilibrium and thermodynamic modelling of the sorption of metals from aqueous 
solution by a silica polyamine composite," Water $S A$, vol. 39, no. 4, pp. 437-444, 2013.

[56] C. Patra, T. Shahnaz, S. Subbiah, and S. Narayanasamy, "Comparative assessment of raw and acid-activated preparations of novel Pongamia pinnata shells for adsorption of hexavalent chromium from simulated wastewater," Environmental Science and Pollution Research, vol. 27, no. 13, article 7979, pp. 14836-14851, 2020.

[57] A. Fenti, P. Iovino, and S. Salvestrini, "Some remarks on A critical review of the estimation of the thermodynamic parameters on adsorption equilibria. Wrong use of equilibrium constant in the Van't Hoof equation for calculation of thermodynamic parameters of adsorption - Journal of Molecular Liquids 273 (2019) 425-434," Journal of Molecular Liquids, vol. 276, pp. 529-530, 2019.

[58] M. Antunes, V. Esteves, R. Guégan, J. Crespo, A. Fernandes, and M. Giovanela, "Removal of diclofenac sodium from aqueous solution by Isabel grape bagasse," Chemical Engineering Journal, vol. 192, pp. 114-121, 2012.

[59] S. Jaerger, A. dos Santos, A. Fernandes, and C. Almeida, "Removal of p-nitrophenol from aqueous solution using Brazilian peat: kinetic and thermodynamic studies," Water, Air, \& Soil Pollution, vol. 226, no. 8, pp. 1-12, 2015.

[60] A. Alene, G. Abate, A. Habte, and D. Getahun, "Utilization of a novel low-cost Gibto (Lupinus Albus) seed peel waste for the removal of malachite green dye: equilibrium, kinetic, and thermodynamic studies," vol. 2021, Article ID 6618510, Journal of Chemistry, 2021.

[61] G. Crini, H. Peindy, F. Gimbert, and C. Robert, "Removal of C.I. Basic Green 4 (Malachite Green) from aqueous solutions by adsorption using cyclodextrin-based adsorbent: Kinetic and equilibrium studies," Separation and Purification Technology, vol. 53, no. 1, pp. 97-110, 2007.

[62] K. Ghosh, N. Bar, A. Biswas, and S. Das, "Elimination of crystal violet from synthetic medium by adsorption using unmodified and acid-modified eucalyptus leaves with MPR and GA application," Sustainable Chemistry and Pharmacy, vol. 19, article 100370, 2021.

[63] I. Ghosh, S. Kar, T. Chatterjee, N. Bar, and S. Das, “Adsorptive removal of Safranin-O dye from aqueous medium using coconut coir and its acid-treated forms: adsorption study, scale-up design, MPR and GA-ANN modeling," Sustainable Chemistry and Pharmacy, vol. 19, article 100374, 2021. 